\title{
ProFile Vortex Instruments after Clinical Use: A Metallurgical Properties Study
}

\author{
Ya Shen, DDS, PhD, * Jeffrey M. Coil, DMD, MSD, PhD, * Hui-min Zhou, DDS, PhD, ${ }^{\dagger}$ \\ Estber Tam, DDS, * Yu-feng Zheng, PhD, ${ }^{\neq}$and Markus Haapasalo, DDS, PhD*
}

\section{Ahstract}

Introduction: The aim of the study was to analyze the incidence and mode of ProFile Vortex instrument (Dentsply Tulsa Dental Specialties, Tulsa, OK) defects during a predefined schedule of clinical use by the undergraduate students in a dental school setting and to examine the metallurgical characteristics of unused and clinically used Vortex instruments. Methods: A total of 2,203 ProFile Vortex instruments discarded after single use from the undergraduate students program over 24 months were collected and examined for defects using a stereomicrosocpe at $10 \times$ magnification. The incidence and type of instrument defects or separation were analyzed. The lateral surfaces of part of the defected instruments and fracture surfaces of fractured files were examined using scanning electron microscopy. Unused and clinically used files were examined by differential scanning calorimetry and $\mathrm{X}$-ray diffraction. Vickers hardness of the files was measured with a $200-\mathrm{g}$ load. Results: Only 1 of the 2,203 files fractured during clinical use. The cause of fracture was shear stress, and the file also showed unwinding of the helix structure. None of the remaining 2,202 files exhibited unwinding after clinical use. Blunt apicals were detected in 86 used files (3.9\%). Austenite-finish temperatures were very similar for as-received, used files with defects and used files without defects, all exceeding $50^{\circ} \mathrm{C}$. No difference in microhardness was detected among these 3 instrument groups. X-ray diffraction results showed that NiTi files had austenite structure at room temperature. Conclusions: The risk of ProFile Vortex fracture is very low when files are used 1 time by undergraduate students. Unwinding of the files was not detected except for the fractured file. Clinical single use had no detectable effect on austenite-martensite phase transformation of the files. Unused and clinical single-use files contain a similar phase structure at body temperature. ( $J$ Endod 2012;38:1613-1617)

\section{Key Words}

Defect, differential scanning calorimetry, endodontic instrument, M-Wire, nickeltitanium instrument, ProFile Vortex, x-ray diffraction

$T^{\text {h }}$ he introduction of nickel-titanium (NiTi) to endodontics over 2 decades ago has dramatically changed the way root canal preparation is performed in both experienced and inexperienced operators' practices. Instruments made of the NiTi alloy, which consists of nickel and titanium in a nearly equal atomic ratio, not only have high resistance to corrosion and excellent biocompatibility but also a special mechanical property known as "superelasticity" (1). Superelasticity is associated with the occurrence of a phase transformation of the alloy upon application of stress above a critical level, which takes place when the ambient temperature is above the so-called austenite-finish $\left(\mathrm{A}_{\mathrm{f}}\right)$ temperature of the material. This stress-induced martensitic transformation reverses spontaneously upon release of the stress; the material then returns to its original shape and size (2). This special property manifests as an enhanced elasticity of the NiTi alloy, allowing the material to recover after large strains. Thus, NiTi instruments are highly flexible and elastic; hence, there is the possibility to use them in a continuous rotary fashion and in a curved canal. Many studies have shown that NiTi rotary systems are able to prepare root canals with desired taper, less canal transportation, and at a much faster rate than hand files (3-5). Despite the advantages, there is concern about the incidence of instrument fractures during root canal preparation $(6,7)$. Two mechanisms that may lead to NiTi rotary fracture, cyclic fatigue, and torsional overloading have been described $(8,9)$. The separation of a rotary instrument in the root canal caused by fatigue in particular has been identified as a primary concern in endodontics especially for root canals with severe curvatures $(9,10)$.

Improvements in metallurgy, surface treatment, design, and quality control and the introduction of hands-on training have reduced the extent of file fracture. Recently, thermal treatment of NiTi alloys (eg, controlled memory wire [CM Wire; DS Dental, Johnson City, TN], M-Wire [Dentsply Tulsa Dental Specialities, Tulsa, OK], and R-phase wire [SybronEndo, Orange, CA]) have been used to modify the mechanical properties. Thermomechanical processing is a frequently used method to optimize the microstructure and transformation behavior of NiTi alloys, which in turn has great influence on the reliability and mechanical properties of NiTi files (11-14). In 2009, ProFile Vortex (Dentsply Tulsa Dental, Johnson City, TN), the "next generation" in the ProFile instrument series was introduced. Vortex files are manufactured from M-Wire; they have a triangular cross-section without radial lands and a helical angle.

A number of studies have examined the failed NiTi instruments collected after clinical use $(6,7,10,15-20)$. Several general observations have been made, which

From the *Division of Endodontics, Department of Oral Biological and Medical Sciences, Faculty of Dentistry, The University of British Columbia, Vancouver, Canada; ${ }^{\dagger}$ Center for Biomedical Materials and Engineering, College of Material Science and Chemical Engineering, Harbin Engineering University, Harbin, China; and ${ }^{\ddagger}$ State Key Laboratory for Turbulence and Complex Systems and Department of Materials Science and Engineering, College of Engineering, Peking University, Beijing, China.

Address requests for reprints to Dr Markus Haapasalo, Division of Endodontics, Department of Oral Biological and Medical Sciences, UBC Faculty of Dentistry, 2199 Wesbrook Mall, Vancouver, BC, Canada V6T 1Z3. E-mail address: markush@dentistry.ubc.ca

0099-2399/\$ - see front matter

Copyright ( 2012 American Association of Endodontists.

http://dx.doi.org/10.1016/j.joen.2012.09.018 
are now considered as contributing factors to instrument fracture, including operator proficiency, method of use, rotational speed, anatomic configuration of the canals, design of the instrument, and number of sterilization cycles. Interestingly, factors related to operators, such as experience, were ranked as the most important $(6,7,21)$. However, little information is available about the new generation of ProFile Vortex files after clinical use. Therefore, the purpose of this study was (1) to analyze the incidence and mode of deformation of this brand of instruments after normal clinical use in an undergraduate student endodontic program over 24 months and (2) to evaluate the impact of clinical use on metallurgical properties (such as the microhardness and phase transformation behavior) of the files.

\section{Materials and Methods}

The ProFile Vortex system was adopted for use by the dental students in the final 15 months of their program at the Faculty of Dentistry, the University of British Columbia, Canada, in 2010-2012. During the period of this study, a full class of 56 fourth-year undergraduate students participated. Cases with very complex, severely curved, or calcified canals were referred to the graduate endodontic program. Each set of Vortex instruments was only used once. After access cavity preparation, canals were negotiated, and the working length was determined using size \#15 K-files. Canal preparation was performed according to the manufacturer's recommendations in a crown-down fashion in the following order: .04 tapered instruments sizes 40, 35, 30, and 25. Size 20 was used only when the size 25 Vortex did not reach to the working length. Apical enlargement was performed by using hand NiTi files to reach size 25 or 30 or Vortex files to increase the apical size to 25 or 30 . The instruments were used in an electric motor with a 1:8 reduction handpiece at $500 \mathrm{rpm}$ (AEU-20 Endodontic System, Dentsply-Tulsa Dental) at the recommended torque values. To eliminate debris accumulation, approximately 0.5 to $1 \mathrm{~mL} 1 \%$ sodium hypochlorite was used as an irrigant between the files. After instrumentation, canals were irrigated with 17\% EDTA. A 30-G side vent needle (Dentsply Tulsa Dental) was used for the irrigation.

Great care was taken to collect all Vortex files after use in the clinic. A total of 2,203 ProFile Vortex instruments were discarded after normal clinical use. All discarded instruments were ultrasonically cleaned, autoclaved, and then examined by 1 investigator under a stereomicroscope (Microdissection; Zeiss, Bernried, Germany) at $10 \times$ magnification. Any defects were noted and classified into one of the following categories: (1) files that seemed intact, (2) unfractured files with defects, and (3) fractured files with or without other defects. The fractured instrument was further cleansed in an ultrasonic bath in absolute alcohol for 90 seconds, and the remaining length was measured using a microscope at $30 \times$ magnification and examined first in the lateral view using a scanning electron microscope (Stereoscan 260; Cambridge Instruments, Cambridge, UK) operating at 8-10 kV. Then, part of the instrument was remounted on the microscope stage, with the fractured surface facing upward, for fractographic examination. The mode of fracture was classified as "fatigue" or "shear" (17).

Differential scanning calorimetry (DSC) analyses were first performed on unused and clinically used Vortex instruments. Test specimens included 3 groups: (1) unused instruments, (2) clinically used instruments without defect, and (3) clinically used instruments that had a defect after use. Ten randomly selected specimens from each group were subjected to the test. Each specimen consisted of 2 segments 4-5 $\mathrm{mm}$ in length and cut from the instruments using a slow-speed, water-cooled diamond saw. Each file had 2 different parts for the DSC test including the apical part (from tip to D5) and the coronal part (D6-D11). The DSC analyses were conducted (PYRIS, Perkin Elmer Diamond Series DSC; PerkinElmer, Shelton, CT) over a temperature ranging from $-100^{\circ} \mathrm{C}$ to $100^{\circ} \mathrm{C}$ by using the liquid nitrogen cooling accessory to achieve subambient temperatures. The detailed procedure has been described previously (22). The transformation temperatures were obtained from the intersection between extrapolation of the baseline and the maximum gradient line of the lambda-type DSC curve. The martensitic transformation-starting and transformation-finishing points ( $\mathrm{Ms}$ and $\mathrm{M}_{\mathrm{f}}$ ) and reverse austenitic transformation-starting and transformation-finishing points (As and $\mathrm{A}_{\mathrm{f}}$ ) were determined.

X-ray diffraction (X'Pert PRO; PANalytical BV, Almelo, The Netherlands) analysis was performed (22-24) in unused instruments, clinically used instruments without defect, and clinically used instruments that developed a defect during use. Analyses were performed on 5 samples each at room temperature $\left(25^{\circ} \mathrm{C}\right)$ with $\mathrm{CuK} \alpha$ monochromatic radiation at $40 \mathrm{kV}$ and a tube current of $100 \mathrm{~mA}$. The detailed procedure has been described previously (22). The peaks were identified by using the pattern library Powder Diffraction File (PDF release 2004; International Centre for Diffraction Data, Newtown Square, PA) by the software MDI Jade5.0 (Materials Data, Inc, Livermore, CA).

An apical segment of 5-6 $\mathrm{mm}$ in length was cut with a water-cooled diamond saw from all instruments for the Vickers microhardness test. Test specimens included 3 groups:

\section{Unused instruments}

2. Clinically used instruments without a defect

3. Clinically used instruments with a defect after use

These segments were mounted and polished by using standard metallographic preparation techniques (25). Vickers microhardness measurements were performed at ambient temperature with a 200-g load and a 15-second dwell time (MicroMet Microhardness Tester, Buehler LTD, Lake Bluff, IL). Three specimens for each group were subjected to the test. Five microindentations were made for each instrument.

The testing data for DSC and microhardness were analyzed statistically by using 1-way analysis of variance, and a comparison of means was conducted by using the Tukey multiple comparison test in software (SPSS for Windows 11.0; SPSS, Chicago, IL) when necessary at a significance level of $P<.05$.

\section{Results}

A total of 2,203 ProFile Vortex instruments were discarded after 1 clinical use. Thirty-three percent of treated teeth were anterior, 33\% were premolars, and the remaining 34\% were molars. Of the 2,203 Vortex instruments collected, only 1 size 20 file was fractured with unwinding. Fractographic examination revealed torsional failure (Fig. 1A-F). Blunting of the file tip was detected in 87 (3.9\%) instruments, but none of these had fractured (Table 1). None of the 2,202 files without fracture exhibited plastic deformation after clinical use. Of the files with tip blunting $(n=86)$, size 25 was the most common $(n=27)$ followed by size $30(n=23)$. The fractured size 20 instrument showed torsional failure (Fig. 1).

There were no differences in the DSC total heat flow for the heating and cooling cycles of test specimens among the unused files and files with or without defects after clinical use (Fig. $2 A$ and $B$ and Table 2). Only a single and defined peak on cooling and heating was detected in all Vortex files; the $A_{f}$ temperature was over $50^{\circ} \mathrm{C}$. The mean $A_{f}$ temperature for clinically used files was nearly identical to the values for the corresponding as-received instrument products $(P>.05)$. Xray diffraction patterns at $25^{\circ} \mathrm{C}$ for diffraction angles $(2 \theta)$ ranging from $20^{\circ} \mathrm{C}$ to $100^{\circ} \mathrm{C}$ contained a major peak for the atomic planes in austenite with no difference among the 3 groups. 
Basic Research-Technology
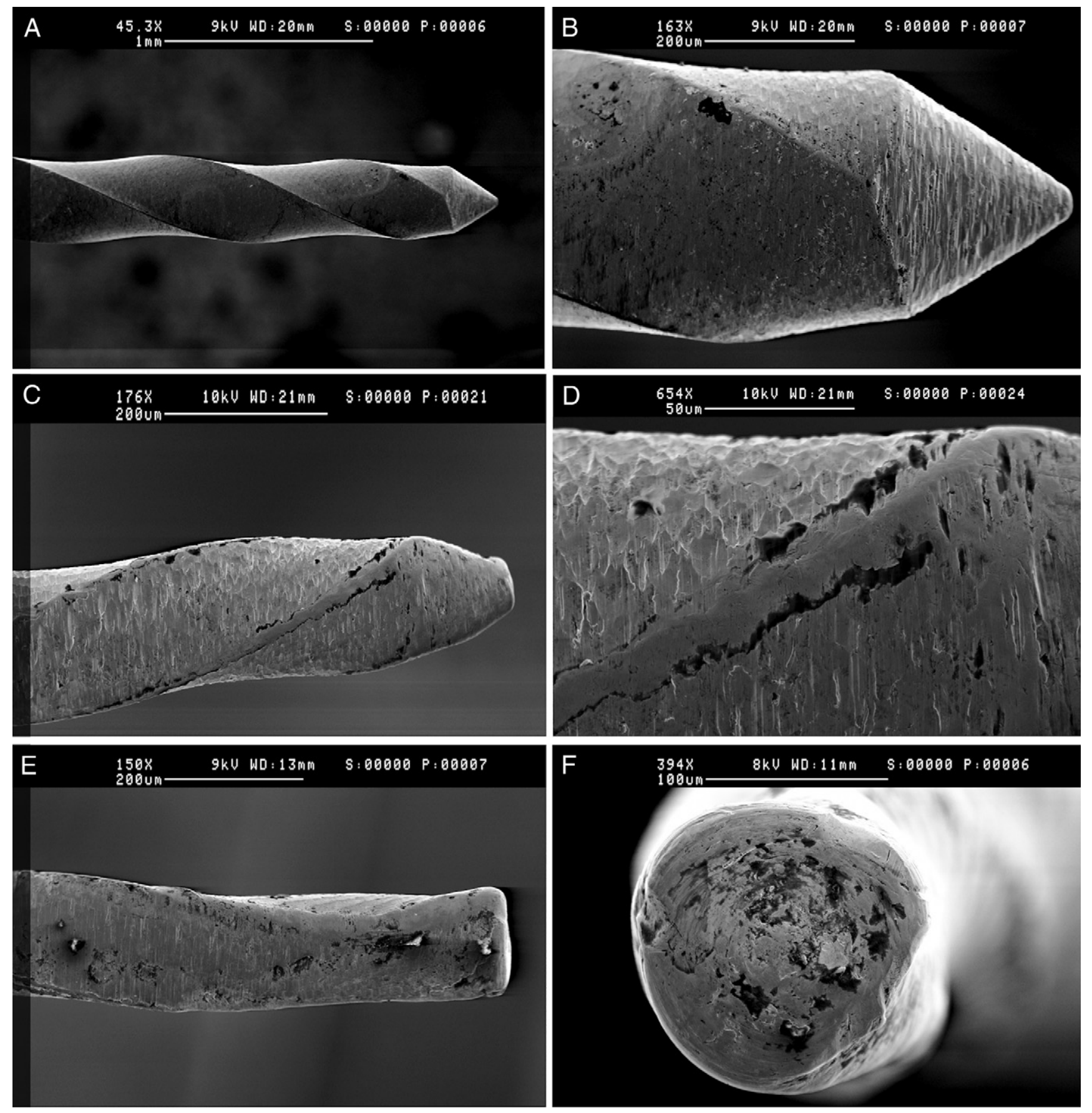

Figure 1. (A) A longitudinal view of an unused Vortex size 40 instrument. $(B)$ A high-magnification view of the tip of an unused file. $(C)$ Apical part blunting in a size 40 file after use. $(D)$ A high-magnification view of the file in $C$. $(E)$ A scanning electron micrograph of a fractured Vortex size 20 instrument. $(F)$ Fracture surface shows typical pattern of torsional failure.

The Vickers microhardness values of the unused and clinically used instruments without defect and apical blunting instruments were $362.3 \pm 28.4,371.9 \pm 36.7$, and $384.1 \pm 37.7$, respectively. The differences in the microhardness of files were not statistically significant $(P>.05)$.

\section{Discussion}

Conventional superelastic NiTi rotary instrument systems have been successfully introduced into the undergraduate endodontic programs for more than a decade $(18,26)$. Despite widespread acceptance, rotary instrument intracanal separation caused by cyclic fatigue has remained a concern in the practice of endodontics, especially for root canals with curvatures $(9,10)$. A few years ago, a modification of the NiTi alloy used for endodontic instruments was developed (27). This new alloy (M-Wire) was composed of SE508 nitinol that had undergone a proprietary method of treatment comprised of drawing the raw wire under specific tension and heat treatments at various temperatures, resulting in a material that includes portions in both the martensitic and the premartensitic R-phase while 
TABLE 1. Occurrence and Type of Defects in Single-Use ProFile Vortex .04 Taper Instruments Used by Undergraduate Students in a Dental School (\% of all instruments)

\begin{tabular}{cccccr}
\hline & & \multicolumn{4}{c}{ Defects } \\
\cline { 3 - 6 } Vortex & $\boldsymbol{N}$ & $\begin{array}{c}\text { Fracture } \\
(\%)\end{array}$ & Unwinding & $\begin{array}{c}\text { Apical blunt } \\
(\%)\end{array}$ & $\begin{array}{c}\text { Subtotal } \\
(\%)\end{array}$ \\
\hline$\# 20$ & 445 & $1(0.2)$ & 0 & $11(2.5)$ & $12(2.7)$ \\
$\# 25$ & 440 & 0 & 0 & $27(6.1)$ & $27(6.1)$ \\
$\# 30$ & 440 & 0 & 0 & $23(5.2)$ & $23(5.2)$ \\
$\# 35$ & 438 & 0 & 0 & $8(1.8)$ & $8(1.8)$ \\
$\# 40$ & 440 & 0 & 0 & $17(3.5)$ & $17(3.5)$ \\
Total & 2203 & $1(0.005)$ & 0 & $86(3.9)$ & $87(3.9)$ \\
\hline
\end{tabular}

maintaining a pseudoelastic state $(22,28)$. According to literature, various forms of the NiTi material (stable or superelastic austenite or stable martensite) have a similar ultimate strength (hence, little impact on torsional [shear] failure) but a different fatigue behavior (29). The superelastic NiTi possesses the lowest fatigue-crack initiation threshold and the worst crack propagation properties among the 3 , the best being the stable martensitic structure (29). Some studies $(28,30$, 31) found that Vortex instruments made from the M-Wire exhibited superior cyclic fatigue resistance compared with those made of regular superelastic NiTi files. Hence, it was perhaps not surprising that the incidence of fracture of ProFile Vortex files with a mixture of austenite and martensite structure at body temperature was extremely low $(1 / 2,203)$ in the present study. Although the detailed information about the thermomechanical treatment history of the Vortex file made from M-wire is not available, it seems that this processing is a very promising way to gain substantial benefits to the safety of endodontic instruments. However, it is important to bear in mind that instrument fracture is a complex multifactorial clinical problem, and many factors such as the operator, root canal anatomy, instrument properties, and usage can influence the fracture.

As a general rule, flexible instruments are not very resistant to torsional load but are resistant to cyclic fatigue. In our study, only 1 file fractured with unwinding because of shear stress. From a mechanical viewpoint, the maximum shear stress always occurs on the surface and is proportional to the shear moment or torque applied, and it is inversely proportional to the third power of radius for a circular cross-section (32). Therefore, given the same torque, smaller instruments would be more susceptible to torsional failure than larger instruments. Shear fracture in conventional superelastic NiTi files has mostly occurred in files of small size $(10,18)$. In the present study, the fracture rate was too low for any conclusions to be drawn regarding the instrument size, but interestingly the only fracture occurred with the smallest file size of \#20.

Recently, Gao et al (31) studied the torsional properties of superelastic wire files, M-Wire files, and Vortex Blue NiTi files. Results showed that M-Wire was 20\% higher in torque strength than superelastic wire and Vortex Blue NiTi, whereas superelastic wire exhibited a slightly higher distortion angle at break than M-Wire. It is possible that the higher torque strength and lower angular distortion (compared with superelastic NiTi wire) makes ProFile Vortex files less likely to undergo such deformations, and, therefore, separation might occur without warning. This position is only indirectly supported by the present study because the extremely low fracture rate does not allow proper comparisons to be made. Manufacturer's instructions affirm that ProFile Vortex instruments are intended exclusively for single use.

The structure of the NiTi alloys, which is central to their clinical performance, is conveniently studied by DSC in which the difference in thermal power supplied to a test specimen and an inert control specimen heated at the same rate is measured very accurately. In the present study, there was no evident effect with the single use of Vortex files on the phase transformation. This is in agreement with another recent study (33) in which no significant difference of $A_{f}$ temperatures (all $A_{f}$ : $50.8^{\circ} \mathrm{C} \pm 0.5^{\circ} \mathrm{C}$ ) was observed for M-Wire samples at 4 different stages of fatigue life (from unused to $90 \%$ fatigue life). The absence of significant work hardening near the tip of the file (from D2 to D6) during use in this study was consistent with our DSC results that the NiTi alloy remains the austenite and martensite structure after clinical use. The study by Ye and Gao (33) found that there was no difference in microhardness between unused and 30\% fatigue life files made of M-Wire. However, microhardness increased as the low cycle fatigue test progressed to and beyond $60 \%$ fatigue life. Although work hardening in the active region may be expected during instrumentation, the use of nanoindenter appears to be necessary to verify the microhardness changes in further research.
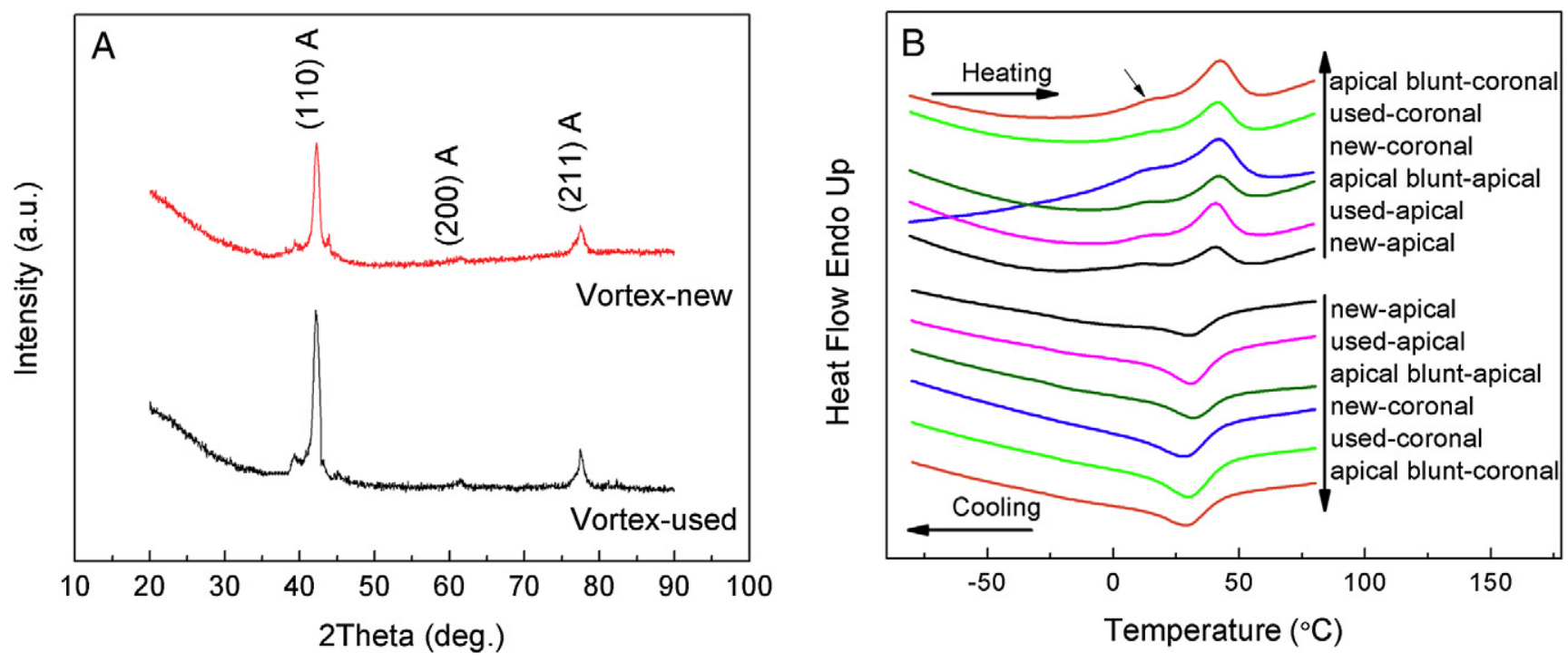

Figure 2. (A) X-ray diffraction of unused and used Profile Vortex files. (B) DSC of unused and used Profile Vortex files. 
TABLE 2. Phase Transformation Temperatures and Associated Energies of Vortex Files (mean \pm standard deviation)

\begin{tabular}{|c|c|c|c|c|c|c|}
\hline \multirow[b]{2}{*}{ Files } & \multicolumn{3}{|c|}{ Heating } & \multicolumn{3}{|c|}{ Cooling } \\
\hline & $\mathrm{A}_{\mathrm{s}}\left({ }^{\circ} \mathrm{C}\right)$ & $A_{f}\left({ }^{\circ} \mathrm{C}\right)$ & $\Delta H_{\text {heating }}(\mathrm{J} / \mathrm{g})$ & $\mathrm{M}_{\mathrm{s}}\left({ }^{\circ} \mathrm{C}\right)$ & $\mathrm{M}_{\mathrm{f}}\left({ }^{\circ} \mathrm{C}\right)$ & $\Delta H_{\text {cooling }}(\mathrm{J} / \mathrm{g})$ \\
\hline New coronal & $-1.1 \pm 2.5$ & $55.9 \pm 1.4$ & $1.6 \pm 0.4$ & $44.1 \pm 1.1$ & $15.6 \pm 1.7$ & $-1.3 \pm 0.3$ \\
\hline New apical & $0.02 \pm 5.4$ & $51.7 \pm 1.4$ & $1.7 \pm 0.1$ & $43.4 \pm 0.7$ & $16.8 \pm 1.1$ & $-1.9 \pm 0.4$ \\
\hline Used coronal & $0.1 \pm 6.7$ & $55.2 \pm 0.1$ & $3.1 \pm 0.1$ & $44.2 \pm 0.8$ & $14.7 \pm 0.5$ & $-1.9 \pm 0.5$ \\
\hline Used apical & $-0.6 \pm 6.4$ & $54.4 \pm 0.5$ & $2.9 \pm 0.02$ & $45.4 \pm 1.1$ & $15.7 \pm 0.3$ & $-2.3 \pm 0.1$ \\
\hline Apical blunt coronal & $-0.5 \pm 4.3$ & $53.4 \pm 0.4$ & $2.1 \pm 0.1$ & $42.4 \pm 0.3$ & $12.6 \pm 2.4$ & $-1.8 \pm 0.4$ \\
\hline Apical blunt apical & $-0.4 \pm 2.0$ & $52.1 \pm 0.5$ & $3.5 \pm 0.02$ & $43.7 \pm 0.3$ & $17.2 \pm 0.2$ & $-3.1 \pm 0.2$ \\
\hline
\end{tabular}

In conclusion, only one ProFile Vortex file $(1 / 2,203)$ fractured during a 2 -year period in an undergraduate clinic. The cause of the fracture was shear stress. Wear of the file tip (apical blunting) was detected in $86(3.9 \%)$ of the files; however, none of these showed unwinding of the helical structure. Clinical single use had no evident effect on the phase transformation of the Vortex files. Unused and clinically singleuse files contain a similar phase structure at body temperature.

\section{Acknowledgments}

The authors deny any conflicts of interest related to this study.

\section{References}

1. Otsuka K, Wayman CM, eds. Mechanism of shape memory effect and superelasticity. In: Shape Memory Materials. Cambridge, UK: Cambridge University Press; 1998:27-48.

2. Saburi T. Ti-Ni shape memory alloys. In: Otsuka K, Wayman CM, eds. Shape Memory Materials. Cambridge, UK: Cambridge University Press; 1998:49-96.

3. Thompson SA, Dummer PMH. Shaping ability of ProFile .04 taper series 29 rotary nickel-titanium instruments in simulated root canals. Int Endod J 1997;30:1-7.

4. Gluskin AH, Brown DC, Buchanan LS. A reconstructed computerized tomographic comparison of NiTi rotary GT files versus traditional instruments in canals shaped by novice operators. Int Endod J 2001;34:476-84.

5. Peters OA, Peters CI, Schönenberger K, Barbakow F. ProTaper rotary root canal preparation: assessment of torque and force in relation to canal anatomy. Int Endod J 2003;36:93-9.

6. Spili P, Parashos $\mathrm{P}$, Messer HH. The impact of instrument fracture on outcome of endodontic treatment. J Endod 2005;31:845-50.

7. Shen Y, Haapasalo M, Cheung GS, Peng B. Defects in nickel-titanium instruments after clinical use. Part 1: relationship between observed imperfections and factors leading to such defects in a cohort study. J Endod 2009;35:129-32.

8. Pruett JP, Clement DJ, Carnes DL. Cyclic fatigue testing of nickel-titanium endodontic instruments. J Endod 1997;23:77-85.

9. Shen Y, Cheung GS, Peng B, Haapasalo M. Defects in nickel-titanium instruments after clinical use. Part 2: fractographic analysis of fractured surface in a cohort study. J Endod 2009;35:133-6.

10. Shen Y, Cheung GS, Bian Z, Peng B. Comparison of defects in ProFile and ProTaper systems after clinical use. J Endod 2006;32:61-5.

11. Gambarini G, Plotino G, Grande NM, et al. Mechanical properties of nickel-titanium rotary instruments produced with a new manufacturing technique. Int Endod J 2011;44:337-41.

12. Gutmann JL, Gao Y. Alteration in the inherent metallic and surface properties of nickel-titanium root canal instruments to enhance performance, durability and safety: a focused review. Int Endod J 2012;45:113-28.

13. Kuhn G, Jordan L. Fatigue and mechanical properties of nickel titanium endodontic instruments. J Endod 2002;28:716-20.

14. Alapati SB, Brantley WA, Iijima M, et al. Micro-XRD and temperature-modulated DSC investigation of nickel-titanium rotary endodontic instruments. Dent Mater 2009;25: $1221-9$.
15. Sattapan B, Nervo GJ, Palamara JE, Messer HH. Defects in rotary nickel-titanium files after clinical use. J Endod 2000;26:161-5.

16. Parashos P, Gordon I, Messer HH. Factors influencing defects of rotary nickeltitanium endodontic instruments after clinical use. J Endod 2004;30:722-5.

17. Cheung GSP, Peng B, Bian Z, et al. Defects in ProTaper S1 instruments after clinical use: fractographic examination. Int Endod J 2005;38:802-9.

18. Shen Y, Coil JM, Haapasalo M. Defects in nickel-titanium instruments after clinical use. Part 3: a 4-year retrospective study from an undergraduate clinic. J Endod 2009;35:193-6.

19. Shen Y, Winestock E, Cheung GS, Haapasalo M. Defects in nickel-titanium instruments after clinical use. Part 4: an electropolished instrument. J Endod 2009;35: 197-201.

20. Shen Y, Coil JM, McLean AG, et al. Defects in nickel-titanium instruments after clinical use. Part 5: single use from endodontic specialty practices. J Endod 2009;35: $1363-7$.

21. Cheung GSP. Instrument fracture: mechanisms, removal of fragments, and clinical outcomes. Endod Topics 2009;16:1-26.

22. Shen Y, Zhou HM, Zheng YF, et al. Metallurgical characterization of controlled memory wire nickel-titanium rotary instruments. J Endod 2011;37:1566-71.

23. Brantley WA, Svec TA, Iijima M, et al. Differential scanning calorimetric studies of nickel-titanium rotary endodontic instruments after simulated clinical use. J Endod 2002;28:774-8.

24. Alapati SB, Brantley WA, Iijima M, et al. Metallurgical characterization of a new nickel-titanium wire for rotary endodontic instruments. J Endod 2009;35: 1589-93.

25. ASTM E3-11. The American Society for Testing and Materials (ASTM): Standard Guide for Preparation of Metallographic Specimens. West Conshohocken, PA: American Society for Testing and Materials; 2007.

26. Knowles KI, Hammond NB, Biggs SG, Ibarrola JL. Incidence of instrument separation using LightSpeed rotary instruments. J Endod 2006;32:14-6.

27. Berendt $\mathrm{CJ}$, Yang $\mathrm{J}$. Endodontic instruments with improved fatigue resistance. In: Berg B, Mitchell MR, Proft J, eds. International Conference on Shape Memory and Superelastic Technologies. Pacific Grove, CA: ASM International; 2006.

28. Johnson E, Lloyd A, Kuttler S, Namerow K. Comparison between a novel nickeltitanium alloy and 508 nitinol on the cyclic fatigue life of ProFile 25/.04 rotary instruments. J Endod 2008;34:1406-9.

29. McKelvey AL, Ritchie RO. Fatigue-crack growth behavior in the superelastic and shape-memory alloy nitinol. Metallurgical and Materials Transactions A 2001;32A:731-43.

30. Gao Y, Shotton V, Wilkinson K, et al. Effects of raw material and rotational speed on the cyclic fatigue of ProFile Vortex rotary instruments. J Endod 2010;36: $1205-9$.

31. Gao Y, Gutmann JL, Wilkinson K, et al. Evaluation of the impact of raw materials on the fatigue and mechanical properties of ProFile Vortex rotary instruments. J Endod 2012;38:398-401.

32. Gere JM. Mechanics of Materials. 5th ed. Pacific Grove, CA: Brooks/Cole; 2001. 187-270.

33. Ye J, Gao Y. Metallurgical characterization of M-wire nickel-titanium shape memory alloy used for endodontic rotary instruments during low-cycle fatigue. J Endod 2012;38:105-7. 